\title{
Diabetes Prevention and Treatments, a Specific Topic for Modern Medicines
}

\author{
Da-Yong Lu ${ }^{1 *}$, Jin-Yu Che ${ }^{1}$, Nagendra Sastry Yarla ${ }^{2}$, Hong-Ying Wu ${ }^{1}$, Ting-Ren Lu ${ }^{1}$ and Hong Zhu ${ }^{3}$ \\ ${ }^{1}$ Shanghai University, China \\ ${ }^{2}$ GITAM University, India
}

${ }^{3}$ Zhejiang University, China

Submission: August 10, 2017; Published: January 25, 2018

*Corresponding author: Da-Yong Lu, Shanghai University, China, Email: ludayong@shu.edu.cn

\begin{abstract}
Diabetes Mellitus (DM) is an old disease in China (over two thousand years) but modern epidemics in western medicines (approximately 100 years). Despite some DM treatment advances, causality, pathogenesis and therapeutics of diabetes is currently too complicated to be easily managed in the clinic. Disease complications (cardiovascular symptoms, vision impairments, nephropathies, chronic leg infections and so on) are more fatal than anti-diabetic control. More importantly, different doctors and pharmaceutical companies often hold different views on DM treatments. To systematically compare between different forms of anti-diabetic therapeutics, new ideas, drug development pipelines, experimental/clinical model establishments and possible future directions are highlighted in this mini-review.

Keywords: Anti-diabetic therapy; Insulin-derivatives; Bee extract; Cardiovascular complication; Traditional chinese medicine; Therapeutic economics
\end{abstract}

\section{Introduction}

Diabetes Mellitus is an old disease in China (over two thousand years) but modern epidemics in western medicines (approximately 100 years). The epidemics of diabetes in China, developing and developed countries have been all growing due to incomplete knowledge towards causality, pathogenesis and therapeutics of diabetes. For this reason, global medical expenses for diabetic diagnosis and treatments are growing steadily [1-4]. Despite some therapeutic advances, diabetes mellitus treatments, especially type 2 diabetes mellitus (T2DM) are generally difficult now. Many key elements relevant to disease causality, pathogenesis and therapy are still unclear. Since diabetic pathogenesis and complications are not well controlled by chemical drugs, state-of-the-art diagnostic techniques and other therapeutic options might be invented.

Unluckily, untrained personnel and many new comers are enthusing for academic credits because they believe experimental models for diabetes mellitus is very easy. Owing to the divergent talents and educational backgrounds, the scientific quality of experimental/clinical diabetes study has been greatly varied. For many new comers, they commonly treat for superficial indicates (by polysaccharide degradation enzyme modulators/inhibitors or others) rather than targeting the origin of disease pathogenesis, such as insulin or genetic related pathways/symptoms. As a tough challenge, new movements must be pursued, promoted and established. This mini-review will address some of them.

\section{Top Challenge}

\section{Building global educational systems}

A lot of people think that diabetes can be easily prevented or treated. A lot of people spoke to a diabetes mellitus patient "do not eat sweet often!" In these people's mind, diabetes is caused by eating too much sweet and can be healed by stopping eating sweets. They never expect that diabetes treatment is still a medical challenge and a lot of people die for diabetesinduced complications. Healthy disseminations and propaganda of scientific diabetes information and knowledge to general audience or potential participants for diabetes studies are indispensable parts of diabetes mellitus epidemics managements worldwide.

In modern diabetes knowledge, diabetes can be found not only in overweight people, but also in lean persons. More recently, the muscle ratios of human bodies are more relevance than merely body weight gains for human blood glucose level up 
and down. In US, only small proportions of diabetes patients are present in US comparing with China, even though approximate same-rates of overweight people between US and PR China. This phenomenon teaches us that high muscle context or ratio in human bodies may also determine human blood glucose levels. These higher muscle context increases can be reached by high quality of human exercises in human beings. If growing number of people are familiar the knowledge, more human beings can benefit life quality and cut down the costs of anti-diabetic treatments greatly.

Developing to type 2 diabetes mellitus (T2DM) might undergo more complex pathogenesis courses in susceptible human beings. Yet the T2DM pathogenesis processes and cascade are often difficult to be reversal. Many preventive measures or food intake control can really slow down the disease progressions but never omnipotent. Some well-established, long-lasting and far-reaching medical education systems for diabetes will be introduced to larger human populations, especially to potential diabetes susceptible old persons.

Since people are commonly asymptotic in early stages of T2DM, good custom buildup, such as reducing high calorie composition food intakes, keeping on animal protein consumptions, increasing physical exercises and so on will be educated into wider people, especially higher diabetes susceptible persons (more than 45 years old or obesity/lean persons). People should be aware that growing high calorie food consumption is not the only factor to trigger T2DM, some other unfavorable factors, such as habitually heavy drunk, genetic mutations or sleep apnea etc [2-6] can also be the culprits for pathogenesis progresses. Thus, regular medical checks including blood glucose concentration detections should be undertook regularly for people more than 45 years old.

The prompt interventions at early stage of diabetes patients are a way of further curbing metabolic complication events and human mortality in diabetes patients. Overall, education to wider audience is an effective ways of reducing diabetes epidemics and human diabetes morbidity.

\section{Deeper understanding about diabetes pathologic and pharmacologic pathways and mechanisms:}

Deeper understanding toward diabetes pathologic and pharmacologic pathways and mechanisms is necessary and indispensable. For many new comers, they are interested on glucose control interfering or sabotaging normal food intake and digestions systems by offering other mono carbohydrate or sugar derivatives for competitive activity. For in depth points of views, most of these efforts are relatively superficial because the top culprit of disease causality and pathogenesis progresses is often not glucose itself. The real pathogenesis causalities of diabetes are mostly of insulin-binding or related, such as loss functions of pancreas island ß-cells [6], liver metabolism [7], insulin resistance [6,7] and other heritable components (malformations of insulin-related molecules by genetic variations, mutations and unfavorable family inherence).

Table 1: Different types of drugs for diabetes mellitus treatments and hyperglycemia control.

\begin{tabular}{|c|c|c|}
\hline Targets & Mechanisms of Action & Personal Opinions \\
\hline Glucose & $\begin{array}{l}\text { Decrease glucose concentrations in animal and human by } \\
\text { glucose metabolism interference } \\
\text { Substitute or compete food glucose intake with other mono } \\
\text { carbohydrates or glucose-derivatives }\end{array}$ & $\begin{array}{l}\text { Controversy } \\
\text { Controversy }\end{array}$ \\
\hline Insulin & $\begin{array}{c}\text { Human insulin and its derivatives } \\
\text { Modulators of pancreatic island ß-cell } \\
\text { Muscle content and insulin-receptor } \\
\text { Pharmaceutical innovations (oral forms of insulin) }\end{array}$ & $\begin{array}{l}\text { First line therapy } \\
\text { Potential } \\
\text { Important } \\
\text { Future trends }\end{array}$ \\
\hline Disease complications & $\begin{array}{c}\text { Cardiovascular complications } \\
\text { Nephropathy } \\
\text { Obesity } \\
\text { Chronic leg infection etc }\end{array}$ & Potential and need to be improved \\
\hline Hepatic functions & Ameliorate of damaged cells and metabolism & Future trend \\
\hline Genetic changes & Gene therapy or other biomedical therapies & Promising \\
\hline Leg ischemic & Surgery & Not satisfactory \\
\hline Life styles & $\begin{array}{c}\text { Educations } \\
\text { Exercise and lifestyle change }\end{array}$ & $\begin{array}{l}\text { Adherence } \\
\text { Persistence }\end{array}$ \\
\hline Targets & Mechanisms of action & Personal opinions \\
\hline
\end{tabular}




\begin{tabular}{|c|c|c|}
\hline Glucose & $\begin{array}{l}\text { Decrease glucose concentrations in animal and human by } \\
\text { glucose metabolism interference } \\
\text { Substitute or compete food glucose intake with other mono } \\
\text { carbohydrates or glucose-derivatives }\end{array}$ & $\begin{array}{l}\text { Controversy } \\
\text { Controversy }\end{array}$ \\
\hline Insulin & $\begin{array}{c}\text { Human insulin and its derivatives } \\
\text { Modulators of pancreatic island ß-cell } \\
\text { Muscle content and insulin-receptor } \\
\text { Pharmaceutical innovations (oral forms of insulin) }\end{array}$ & $\begin{array}{l}\text { First line therapy } \\
\text { Potential } \\
\text { Important } \\
\text { Future trends }\end{array}$ \\
\hline Disease complications & $\begin{array}{c}\text { Cardiovascular complications } \\
\text { Nephropathy } \\
\text { Obesity } \\
\text { Chronic leg infection etc }\end{array}$ & Potential and need to be improved \\
\hline Hepatic functions & Ameliorate of damaged cells and metabolism & Future trend \\
\hline Genetic changes & Gene therapy or other biomedical therapies & Promising \\
\hline Leg ischemic & Surgery & Not satisfactory \\
\hline Life styles & $\begin{array}{l}\text { Educations } \\
\text { Exercise and lifestyle change }\end{array}$ & $\begin{array}{l}\text { Adherence } \\
\text { Persistence }\end{array}$ \\
\hline
\end{tabular}

Table 1 Due to these forms of therapeutic limitations, diabetes therapeutic study needs to be retrospective investigations. New experimental or clinical models must be established. Current pathogenesis and mechanisms of action of anti-diabetic drugs are outlined in Table $1[8,9]$. Since there are many shortcomings and drawbacks in chemical anti-diabetic drugs, these chemical therapeutic drugs many times could not play decisive roles in completely managements of diabetes events and symptoms. New generations of anti-diabetic therapeutic drugs must be developed.

\section{Personalized diabetes therapy (PDT), if a possible solution ready}

Since the clinical symptoms and stages of diabetes patients vary greatly in clinics, treatments for different types or stages of diabetes should not be uniform. Personalized anti-diabetic therapy (PDT) may be a modern possibility that enable us to offer better therapeutics for individual diabetes patients. Nonetheless, PDT is not restricted for clinically pharmacogentics (PG) studies alone as it is now [8-16]. At this stage of technical capability, PG study mainly aims at drug dosage and concentration prediction in patients' pharmacodynamics or pharmacokinetics by detecting polymorphisms of human metabolic enzymes or modern chromatography. Since diabetes can be divided into categories of type one or two, different ranges of disease-related molecular elements and disease-induced metabolic complications in diabetes patients must be studied in patients individually. Genetic or bioinformatics detection of diabetes pathological profiling is the important foundation of PDT study. Figure 1 represents the outlook and different possibilities of PDT. This type of PDT may be utilized in future anti-diabetic treatments and help to patients possibly [9].

\section{Patient enrollments}

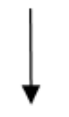

Disease notifications

(Blood glucose or insulin levels)

Disease symptoms and complications



(Genetic, molecular and physiological)

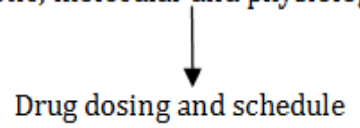

(Pharmacogenetics, modern chromatography and so on)

Therapeutic decision-making

Figure 1: Proposed diagram of personalized diabetes therapy.

\section{Pharmaceutical and Pharmacologic Studies}

\section{Drug development}

Development of higher therapeutic index drugs is always the ultimate goals of drug developers and pharmaceutical companies. Likelihood, it is one of the major avenues of diabetes mellitus therapeutic study and clinical applications [17-22]. Many synthetic anti-diabetic drugs may have low therapeutic index in human bodies. As the safest and first-line anti-diabetic therapeutics, insulin and insulin-derivatives can be used in both 
type I and type II diabetes patients according to different clinical situations [19].

From our perspective, we do not suggest the widely insulinutilities while patients' blood level is below $10 \mathrm{nmol} / \mu \mathrm{l}$. It is very difficult to adjust insulin dosage in these patients. It also has some obvious drawbacks syringes and injections are needed every day, which lead to treatment inconvenience. Currently, oral intake of drugs is the most welcoming and environmental-friendly for all patients. Thus, some small-molecular chemicals having the insulin-configurations or insulin receptors binding activity might be potential oral anti-diabetic drugs for surrogating insulin in the clinic.

In future, we can compare, calculate and simulate insulinconfigurations or insulin receptors binding sites from large-pool of small-molecular chemical pipelines by computing or medical investigations [17]. If this type of breakthrough can be achieved, new generations of highly effective, pharmaceutical-friendly chemical agents might be discovered and licensed. More recently, it has been invented that some capsules containing insulin can be given to diabetes patients. This pharmaceutical innovation can achieve great success in future diabetes treatments.

\section{Natural therapeutic drug developments}

Owing to the shortcomings of synthetic chemical drugs in DM therapies, many natural plants or organisms are proposed for hyperglycemia and disease complication managements, especially in China. They are commonly crude plant, insect or animal products. Crude plants are leaf of cyclocarya paliurus, mulberry leaf and root of remembranous milk vetch etc. Similar as anticancer drug developments [23], natural existing compounds are often low toxicity and higher therapeutic efficacies and index than synthetic chemical agents [24]. Mild therapeutic characteristics of crude plants may be as assistant therapeutics with insulin or other DM therapeutic agents.

Some insect products such as propolis are also widely recognized in diabetes treatments [8-9, 25]. Propolis is bee extract of waxy-like components extracted from crude honey. It has been discovered for anti-bacterial, anti-fungal, anti-tumors and so on [25]. In China, it has been licensed as healthy-promoting agents yet practiced as hyperglycemia control. Now it has been largely sold and received popularity for its efficacy for DM treatments in China. Many reputed traditional Chinese Medicine (TCM) Pharmaceutical Companies of long history are all manufactured and sold propolis. It is characterized as drug combinations in DM treatment. Nonetheless, propolis is expensive in China (50-100 USD for one bottle of propolis capsule). Large-scale, doubleblind cohort clinical evaluations are still needed to standardize DM therapies by propolis in future.

To attain the goal of DM therapeutic improvements, similar alterations or therapeutic guidelines should also be proposed, cooperatively studied, testified and finally verified by experimental, preclinical or clinical studies worldwide. Apart from China, many plant, insect or animal components have also been used for anti-diabetic managements. In Japan, some fermented soy beans are also famous for diabetes and metabolic complication therapeutics and improvements.

\section{Drug combinations}

Since diabetes can exhibit wider ranges of clinical symptoms, variant complications and pathogenic pathways in different individuals must be treated with different formula of drugs. To build up high quality of drug combination strategies, both experimental and clinical medical studies are much needed. By these scientific efforts, clinical diabetes treatments might be updated in future. Currently, even many drug combinations have been utilized in clinics, theoretical medical studies are lag behind. Now clinical drug combinations are from doctors' empirical and instinct rather than scientifically supported. In future, clinical drug combination should be mathematically analyzed. This type of medical work must be based on diabetes pathologic studied and evaluated from every possibilities, like cancer treatments [26-28]. Let's pay more attentions on that.

\section{Biotherapy for diabetes treatments}

Since diabetes is an endocrinologic disease, human bimolecular (such as insulin, micro-RNA and so on), we believe might be more effective and less toxic than chemotherapeutic drugs (commonly licensed drugs). However, most of bimolecular are short-live. Thus, pharmaceutical processes to add bimolecular with organic ligands/chains are commonest ways in medicinal chemistry [19]. These processes are commonly less toxic and long-live in human-bodies.

\section{Budget control in drug developments}

Drug manufactory is adventurous, which is a highly competitive and risky industry worldwide. Nevertheless drug discovery, development and manufacture have been entering into bottleneck stages [29-30]. Greater sum of money is investing for drug developments. The whole process of drug licensing need 1-2 billion USD in US and other developed countries [29$30]$. Thus, enough carefulness in drug developments and clinical utilities is necessary and noteworthy.

\section{Other preventive and therapeutic options}

Healthy lifestyle and good behaviors: Encouraging diabetes patients to change thei

lifestyle is proved to be of great medical significance. In previous reports, large body of literatures and research projects target on proper exercise (such as Qi-Gong from Chinese, Yoga from India and other physical exercises in western countries) is very useful for diabetes patients [31]. Furthermore, more diabetes patients should be encouraged to do some exercise that can consume most glucose in patient's blood and balance the human metabolic systems from its sources. 
Table 2: Major diabetes-induced complications in patients.

\begin{tabular}{|c|c|}
\hline Complication Locations & Specific Types \\
\hline \multirow{2}{*}{ Metabolic } & Cardiovascular (atherosclerosis, \\
hypertension) & Obesity \\
& Muscle malformations \\
& Infections (chronic leg infections) \\
\hline Eye complications & Visual damage and blur \\
& Cataract \\
& Fundus hemorrhages and vessel \\
& leakage \\
\hline Kidney failure & Nephropathy \\
\hline Brain damage & Brain retardation \\
& Cognitive impairments \\
\hline
\end{tabular}

To build-up strong muscles in diabetes patients, balance diet (enough animal proteins in foods) and high quality of exercises (physical exercises) might be more useful comparing with merely diet limitation alone. Without enough food animal protein and exercises, patient's muscles will be gradually lost and further drug treatments will be compromised. Generally speaking, exercise in diabetes patients is as equal importance as chemical or biological interventions for hyperglycemia conditions.

\section{Disease complications treatments}

Diabetes complications are many times very serious for patients suffering hyperglycemia over 5 to 10 years. Large parts of disease complications are difficult to be successfully reversal. Diabetes complications treatment study and applications should be drawn more attentions in future. Major diabetes complications are represented in Table 2. Thus new generations of anti-diabetic therapeutic agents or drugs must be designed and finally licensed in order to manage these complications. This strategy is an indispensable route to move on, yet difficult to achieve presently.

\section{Future perspectives}

Since growing number of people are suffered from diabetes and related complications worldwide (doubled disease rates in the past two decades), diabetes therapy studies need to be promoted. Persistent efforts and novel ideas must be established. Table 3 illustrates roadmap and major avenues for achieving fruitful diabetes therapeutics in future.

Table 3: Hotspots for anti-diabetic study and clinical therapeutics.

\begin{tabular}{|c|}
\hline \begin{tabular}{c} 
Development of high-indexed synthetic or natural anti-diabetic drugs \\
\hline $\begin{array}{c}\text { Educate broader ranges of audience to understand the basic knowledge of diabetes. As a result, diabetes can be properly noticed and treated on } \\
\text { disease onset. }\end{array}$ \\
Deeper understanding the relationships between pathogenesis and therapeutics
\end{tabular} \\
$\begin{array}{r}\text { Genetic or molecular study of disease progression, drug pharmacology, mechanisms of action for drug activities and toxicities among different } \\
\text { individuals, ethnic groups and largest populations of different countries. }\end{array}$ \\
Personalized diabetes therapy (PDT) establishments and wider utility in the clinic \\
\hline Establish the relationships between hyperglycemia and disease complications \\
\hline To find out natural products or drugs from plants, insects and animals such as propolis \\
Drug combination study, both experimentally and clinically \\
Strengthen investigations for biotherapies \\
Budget control in drug developments and cost-effective in clinical treatment selections \\
\hline Genome wide association study (GWAS) between patients and normal people \\
Pharmaceutical innovation of insulin treatments from needle to oral \\
Global cooperation is inevitable
\end{tabular}

Despite many achievements, only limited therapeutic agents (such as insulin) can be completely reliable. Rapid development of useful anti-diabetic drugs, especially for diabetes-induced complications, is the top priority and of great medical significance [32-35]. Since the relationship between hyperglycemia and disease-complications has not been fully established, complete therapeutic options are long-way to go. This is a major drawback in anti-diabetic therapeutic and disease complication managements.

Since too much diabetes components and pathways can be changed, more patents for anti-diabetic treatments are welcome across the world [36,37]. Many anti-diabetic therapies are at their initial stages owing to tight budgets in diabetes studies in developed countries, such as US [2]. Growing supports from personnel to research funds are indispensable. For genetic study of T2DM occurrence, progressions and complications, large scale genome wide association study (GWAS) can be very useful but still costly. Of course, these types of genomic studies welcome mathematic- or physic-majored talents [38,39]. As most patients with T2DM (>85\%) are come from developing countries yet the developed countries have good technical supports and large parts of research funds, joint-efforts between developed countries 
and developing countries seem to be mutual benefits. Winwin situation decides healthy progresses in diabetes treatment studies and clinical applications. After global cooperation, both extremes of human populations can be provided with high quality of anti-diabetic medications, especially PDT.

\section{Conclusion}

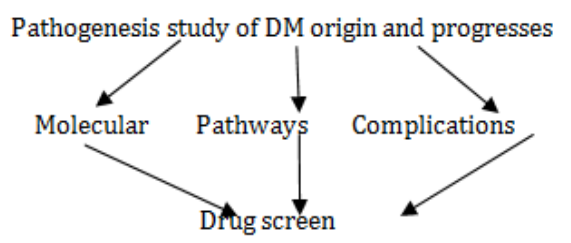

(Synthetic, natural and biological)

$$
\text { Preclinical and clinical }
$$

(ADME, tolerance and toxicity)

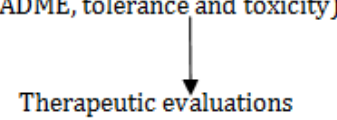

(Symptom control and statistics)

Drug combinations

(Evidence collections and theoretic)

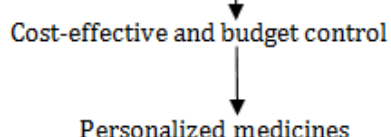

Figure 2: Overall drug development and clinical utilities.

Treatment of diabetes is still a medical challenge for pathogenesis process and complication managements. The importance of educational introductions of diabetes pathogenesis and therapeutic knowledge is a good route in diabetes epidemic control. In future, new perspectives and scientific investigations will be implemented for changing current anti-diabetic therapeutic outcomes for good.

\section{Acknowledgement}

This work was funded by Shanghai Science and Technology Foundation of High Educations 97A49

\section{References}

1. Yang WY, Lu JM, Weng JP, Jia W, Ji L, et al. (2010) Prevalence of diabetes among men and women in China. New Engl J Medicine 362(12): 10901101.

2. Zimmet PZ, Magliano DJ, Herman WH, Shaw JE (2014) Diabetes; a 21st century challenge. Lancet Diabetes Endocrinol 2(1): 56-64.

3. Fuchs S, Henschke C, Blumel M, Busse R (2014) Disease management programs for type 2 diabetes in Germany; a systematic literature review evaluating effectiveness. Dtsch Arztebl Int 111(26): 453-463.

4. Thepworgsa I, Kirby C, Schattner P, Shaw J, Piterman L, et al. (2014) Systematic review or meta-analysis type 2 diabetes continuing medical education for general practitioners: what works? A systematic review. Diabetic Med 31(12): 1488-1497.
5. Nannapaneni S, Ramar K, Surani S (2013) Effect of obstructive sleep apnea on type 2 diabetes mellitus; a comprehensive literature review. World J Diabetes 4(6): 238-244.

6. Grimaccia F, Kanavos P (2014) Cost, outcome, treatment pathways and challenges for diabetes care in Italy. Global Health 10(1): 58.

7. Wens J, Vermeire E, Hearushaw H, Lindenmeyer A, Biot Y, et al. (2008) Educational interventions aiming at improving adherence to treatment recommendations in type 2 diabetes. A sub-analysis of a systematic review of randomized controlled trials. Diabetes Research and Clinical Practice 79(3): 377-388.

8. Lu DY, Che JY, Wu HY, Lu TR (2014) The pathogenesis and treatments of diabetes, questions and answers. Cell \& Developmental Biology 3(3): 126.

9. Lu DY, Che JY, Wu HY, Lu TR (2014) The pathogenesis and treatments of diabetes, a new insight. Advanced Techniques in Biology \& Medicine 2: 102 .

10. Asche C, Lafleur J, Conner C (2011) A review of diabetes treatment adherence and the association with clinical and economic outcomes. Clinical Therapeutics 33(1): 74-109.

11. Mattews DR, Hoster JP, Rudenski AS, Naylor BA, Treacher DR, et al. (1985) Homeostasis model assessment: insulin resistance and $\beta$-cell functions from fasting plasma glucose and insulin concentrations in man. Diabetologia 28(7): 412-419.

12. Maida A, Lamont BJ, Cao X, Drucker DJ (2011) Metformin regulates the incretin receptor axis via a pathway dependent on peroxisome proliferator-activated receptor- $\alpha$ in mice. Diabetologia 54 (2): 339349.

13. Evans WE, Johnson JA, (2001) Pharmacogenomics: the inherited basis for interindividual differences in drug response. Ann Rev Genomics and Human Genetics 2: 9-39.

14. Evans WE, Relling MV, (2004) Moving towards individualized medicine with pharmacogenomics. Nature 429(6900): 464-468.

15. Goldstein DB, Tate SK, Sisodiya SM (2003) Pharmacogenetics goes genomic. Nature Rev Genetics 4(12): 937-947.

16. Correa-Giannella ML, Machado UF (2013) SLC2A4 gene: a promising target for pharmacogenomics of insulin resistance. Pharmacogenomics 14(8): 847-850.

17. Lu DY, Che JY (2014) Rethink of diabetes treatment and drug development. Cell \& Developmental Biology 3(2): e125.

18. Sattar N (2014) Advances in managing type 2 diabetes: challenging old paradigms and developing new one. F1000Prime Reports 6: 42.

19. Rys P, Pankiewicz O, Lach K, Kwaskowski A, Skrzekowska-Baran I, et al. (2011) Efficacy and safety comparison of rapid-acting insulin aspart and regular human insulin in the treatment of type 1 and type 2 diabetes mellitus; a systematic review. Diabetes \& Metabolism 37(3): 190-200.

20. Henry RR, Chilton R, Garvey WT (2013) New options for the treatment of obesity and type 2 diabetes mellitus (narrative review). Journal of Diabetes and its Complications 27(5): 508-518.

21. Turpin SM, Hoy AJ, Brown RD, Garcia Rudaz C, Honeyman J, et al. (2011) Adipose triacylglycerol lipase is a major regulator of hepatic lipid metabolism but not insulin sensitivity in mice. Diabetologia 54(1): 146-156.

22. Davis TME, Ting R, Best JD, Donoghoe MW, Drury PL, et al. (2011) Effects of fenofibrate on renal function in patients with type 2 diabetes mellitus, the Fenofibrate Intervention and Event Lowering in Diabetes (FIELD) study. Diabetologia 54(2): 280-290.

23. Ali I, Saleem K, Uddin R, Haque A, El-Azzouny A (2010) Natural 
products: human friendly anti-cancer medications. Egypt Pharm J (NRC) 9(2): 133-179.

24. Lu DY, Lu TR, Lu Y, Sastry N, Wu HY (2016) Discover natural chemical drugs in modern medicines. Metabolomics 6(3): 181.

25. Wagh VD (2013) Propolis: a wonder bees product and its pharmacological potentials. Adv Pharmacol Sci 2013(2013): 11.

26. Lu DY, Chen EH, Lu TR, Ding J (2015) Anticancer drug combinations, studies from different pathways. Cell \& Developmental Biology 4: 166.

27. Lu DY, Chen EH, Lu TR, Ding J (2016) Anticancer drug combinations, studies for all possibilities. Advances in Pharmacoepidemiology \& Drug Safety 5(1): 138.

28. Lu DY, Chen EH, Wu HY, Lu TR, Xu B, et al. (2016) Anticancer drug combination, how far we can go through?. Anticancer Agents Med Chem 17(1): 21-28.

29. Merris J (2005) Productivity counts-but the definition is key. Science 309(5735): 726.

30. Lu DY, Lu TR, Chen EH, Xu B, Yarla NS, et al. (2017) Anticancer drug development, system updating and global participations. Current Drug Therapy 12(1): 37-45.

31. Freire MDM, Alves C (2013) Therapeutic Chinese exercises (Qigong) in the treatment of type 2 diabetes mellitus: a systematic review. Diabetes \& Metabolic Syndrome: Clinical Research \& Reviews 7(1): 56-59.

32. Leroux C, Brazeau AS, Gingras V, Desjardins K, Strychar I, et al. (2014) Lifestyle and cardiometabolic risk in adults with type 1 diabetes: a review. Canadian J Diabetes 38(1): 62-69.
33. Inan B, Aydin U, Ugurlucan M, Aydin C, Teker ME (2013) Surgical treatment of lower limb ischemia in diabetic patients-long-term results. Arch Med 9(6): 1078-1082.

34. Knowler WC, Bahnson JL, Bantle JP, Bertoni AG, Bray GA, et al. (2014) Effect of a long-term behavioural weight loss intervention on nephropathy in overweight or obese adults with type 2 diabetes: a secondary analysis of the Look AHEAD randomised clinical trial. Lancet Diabetes Endocrinol 2(10): 801-809.

35. Li GW, Zhang P, Wang JP, An Y, Gong Q, et al. (2014) Cardiovascular mortality, all-cause mortality, and diabetes incidence after lifestyle intervention for people with impaired glucose tolerance in the Da Qing diabetes prevention study: a 23-year follow-up study. Lancet Diabetes Endocrinol 2(6): 474-480.

36. (2012) Use of (3-trihalomethylphenoxy)(4-halophenyl) acetic acid derivatives for treatment of type 2 diabetes, US8329749. Metabolex Inc, USA.

37. (2012) N-linked heterocyclic receptor agonists for the treatment of diabetes and metabolic disorders, US20120322804A1 Metabolex Inc, USA

38. Lu DY, Lu TR (2015) Mathematics or physics-majored students on the biomedical fields, insiders or outsiders?. Metabolomics 6: 142 .

39. Lu DY, Wu HY, Lu TR, Che JY, Lu Y, et al. (2016) Updating biomedical studies by recruiting more mathematics or physics-majored talents. Metabolomics 6: 148 .
Your next submission with Juniper Publishers will reach you the below assets

- Quality Editorial service

- Swift Peer Review

- Reprints availability

- E-prints Service

- Manuscript Podcast for convenient understanding

- Global attainment for your research

- Manuscript accessibility in different formats

( Pdf, E-pub, Full Text, Audio)

- Unceasing customer service

Track the below URL for one-step submission https://juniperpublishers.com/online-submission.php 